\title{
Commissioning laboratory services
}

\author{
R D Turner
}

\begin{abstract}
Scientists often develop techniques that have obvious benefits for patients but then find great difficulty in introducing them into the National Health Service-usually because the necessary finance does not seem to be available. This article provides a practical guide.
\end{abstract}

(f Clin Pathol: Mol Pathol 2001;54:225-226)

Keywords: hospital trusts; National Health Service; commissioning laboratory services

Write to any primary care trust, health authority, or hospital trust chief executive in the country asking whether they could find a few thousand pounds for a new and very interesting service or technology that might potentially save a number of lives, and the answer will not immediately be forthcoming. The chief executive will send a polite holding letter to the applicant(s) and will pass the letter to a commissioning manager or operational manager for the service in question, with a request for an opinion, in the full knowledge that all available funds have been committed for the year and that there are demands from several other services that are already outstanding. The operational manager will look to see whose name is on the bottom of the letter and then ask colleagues in his or her office for comments. He may well arrange to meet with the applicants and, depending on whether or not he is interested in what is heard, will either champion the application through to the commissioning stage or will back out-quoting pressure on resources, etc. The main point is that resource allocation is not a mechanical, scientific, or even logical process. It depends very much on what those in charge of distributing the budget see as being important.

No public body keeps a fund set aside just in case any interesting new developments come along. Each one is obliged to spend their entire allocation every year without carryover into the next year (although three year planning is becoming a little more accepted in theory). In order to pay Peter to take on additional work it is normally necessary to rob Paul, unless new money has been ring fenced for a particular development. Spending money in the National Health Service (NHS) is an active process in which managers have to keep a range of stakeholders satisfied. These fall into five main categories, namely:

(1) Ministers, who may have made promises to the public (for example, that waiting list sizes will come down).

(2) Clinicians, who sometimes write to members of parliament, etc if they feel that patients will die unless a further investment is made in a particular service.
(3) Heads of department who can either demonstrate that the service they provide will be much more cost effective and/or safer if the new development takes place, or that the service will collapse if it does not take place.

(4) Patient groups (such as the Multiple Sclerosis Society) that can publicise the fact that the service provided in a given locality is out of date or not nearly as good as it should be. (5) Other managers in the same organisation who have a particular wish to develop a given aspect of the services that they are responsible for.

If new money is not available, and a given objective has to be achieved, then there are ways in which almost any development can be financed. However, it takes courage, skill, and determination for a manager to transfer cash out of one budget and into another, as well as a judgement that the losers will not have a sufficiently strong case to get the decision reversed by someone with more authority-right up to the prime minister or the High Courts. Managers who take wrong decisions may lose out personally, either in the promotion stakes or at the next reorganisation.

New money from the Department of Health as announced by ministers in parliament is almost always earmarked for a particular purpose these days, but this may be in fairly general terms such as "reducing mortality from heart disease". Applicants with a very specific test or procedure in mind who can make a clear connection between their application and the purpose identified in the letter from the Department of Health accompanying the funds (not to mention timescales, etc) will have a considerable advantage, and potential applicants therefore need to keep themselves informed of such grants as they are made available every year. Those who do not attend meetings to discuss how these grants should be spent may find themselves overlooked.

Given an interesting development in-for example-molecular pathology, then how should laboratory managers go about securing investment in their specialty to introduce it?

A possible sequence of events might be:

(1) Assemble the evidence of effectiveness for the new procedure. Is it genuinely ready to be introduced as a service rather than being submitted as a research project?

(2) Demonstrate why new investment is required rather than a redeployment of existing resources. Managers will ask whether any new test could be funded by cutting out or reducing "traditional" tests or investigations.

(3) If the new technique would save money in other areas (for example, by reducing the amount of inpatient, outpatient, or community care over the duration of the patient's illness), as well as improving the quality of life for the 
defined group of patients, then seek the support of managers, clinicians, and patient support groups in these areas. Genetic tests that could reduce the demand for colonoscopies could well be self financing-for example, quite apart from saving many patients from the entire screening procedure.

(4) Invite those managers or clinicians who will be affected by the introduction of the new service to come to a meeting and help construct a business case, and include representatives from primary care trusts if funding is required from them. Do not leave anybody out, particularly at the first meeting. Ideally, ask one of the trust managers to write the business case, but in any event, ask them to sign it when they are satisfied with it. People tend to support cases that they have been involved in constructing.

(5) Consider as many angles as possible when preparing the business case (for example, benefit to the patient, cost to the patient, benefit to the NHS, and cost to the NHS). Find out whether there are any funded national, regional, or local initiatives that might be fully or partially achieved by the introduction of this development. Examples include health improvement programmes, waiting list initiatives, new opportunity funds, national service framework funds, etc. If patient groups, community health councils, voluntary organisations, or members of parliament are pressing for the development, then this should be stated. When the development has been the subject of recent press or television coverage, this is also worth mentioning. Lay members of committees and members of parliament are often informed by these programmes.

(6) Quantify as much as possible (accommodation, staff, equipment, consumables, cost, timescales, and target dates by which demonstrable improvements will have occurred).

(7) Persevere. If the application is genuinely useful, seek the support of organisations such as the Royal Colleges and ask them to write a report supporting introduction, either on a pilot basis or on a wider scale. Quote other similar institutions where it has already been introduced, either locally or further afield. Resubmit the application next year if the initial application fails.

Many trusts and authorities have a standard proforma for use in preparing business cases, and where these are completed in full then no one can complain that they have not been given all the information they require.

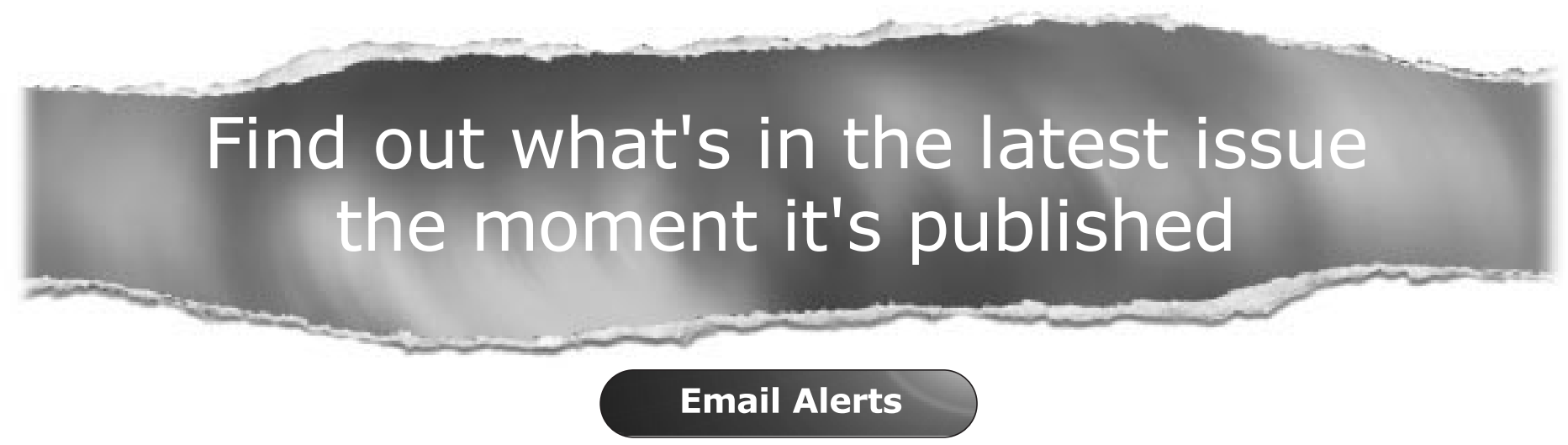

Sign up to receive the table of contents by email every month. You can select from three alerts: Table of Contents (full), TOC Awareness (notice only); Journal of Clinical Pathology related announcements.

\section{www.jclinpath.com}

